\title{
Pós-tratamento de efluentes de indústria de laticínios por processos de separação por membranas
}

\author{
Post-treatment procedures dairy industry wastewater separation membrane
}

\author{
Douglas Felipe Galvão $\left.{ }^{1}{ }^{*}\right)$ \\ Eliane Rodrigues dos Santos Gomes ${ }^{2}$
}

\section{Resumo}

As indústrias de laticínios geram grandes volumes de efluentes em seus processos produtivos. Tal efluente se não tratado e lançado diretamente em corpos hídricos pode causar diversos problemas como eutrofização e eliminação da fauna aquática. Com padrões de lançamento mais restritivos, o interesse por processos de tratamento que gerem efluente tratado de maior qualidade ganham relevância. Os processos de separação por membranas têm despertado interesse especialmente pela capacidade de geração de efluentes de boa qualidade, através de sistemas compactos de tratamento e que não necessitam de produtos químicos, somente durante a limpeza das membranas. O presente estudo teve como objetivo estudar processos de separação por membranas no tratamento de efluente de um laticínio da região Oeste do Estado do Paraná. Foram utilizadas membranas de microfiltração e ultrafiltração, obtendo-se eficiências de tratamento de 100\% para turbidez e sólidos sedimentáveis e acima de 90\% para DQO e $\mathrm{DBO}_{5}$.

Palavras-chave: Leite. Microfiltração. Ultrafiltração. Efluente. Separação.

\section{Abstract}

The dairy industries generate large volumes of waste in their production processes. This effluent is not treated and released directly into water bodies can cause many problems such as eutrophication and elimination of aquatic fauna. With more stringent discharge standards in legislation, interest in treatment processes that generate higher quality treated effluent gain relevance. The separation processes by membranes have generated interest especially the ability to generate good quality effluent by treatment systems compact and does not require chemicals, only during cleaning of the membranes. This study aimed to study membrane technology to treat effluent from a dairy in western Paraná. Microfiltration and ultrafiltration membranes were used to give $100 \%$ treatment efficiencies for turbidity and settleable solids and up to 90\% COD and $\mathrm{BOD}_{5}$.

Keywords: Milk. Microfiltration. Ultrafiltration. Effluent. Separation.

1 Me.; Programa de Pós-Graduação em Tecnologias Ambientai; Universidade Tecnológica Federal do Paraná - Campus Medianeira, UTFPR, Brasil; Assistente em Administração na Universidade Federal da Integração Latino Americana - UNILA; Endereço: Universidade Federal da Integração Latino-Americana. Avenida Sílvio Américo Sasdelli, Vila Residencial A.CEP: 85866000 - Foz do Iguaçu, PR - Brasil; E-mail: fgdoug@gmail.com (*) Autor para correspondências

2 Dra.; Engenharia Química; Universidade Estadual de Maringá, UEM, Brasil; Professora no curso de graduação em Engenharia Ambiental da Universidade Tecnológica Federal do Paraná, UTFPR; Endereço: Universidade Tecnológica Federal do Paraná, Campus Medianeira. Avenida Brasil, 4232, Parque Independência. CEP: 85884-000 - Medianeira, PR - Brasil; E-mail: elianegomes@utfpr.edu.br

\begin{tabular}{llllll}
\hline Ambiência & Guarapuava (PR) & v.14 n.3 & p.594-613 & Set/Dez 2018 & ISSN $1808-0251$
\end{tabular}




\section{Introdução}

As indústrias são grandes consumidoras de água em seus processos produtivos, sendo responsáveis por, aproximadamente, 20\% do consumo mundial de água (MILLER JR., 2008).

A indústria de laticínios é responsável pelo consumo de elevado volume de água, sendo o recurso natural mais utilizado no setor. A necessidade dela ocorre, principalmente, pela manutenção de condições de limpeza, sanitárias e de higiene dentro dos setores de produção (MAGANHA, 2008).

Com padrões de lançamento de efluentes mais restritivos e a necessidade de preservação e conservação de recursos hídricos, torna-se fundamental o tratamento dos efluentes antes de seu lançamento.

Nesse sentido, torna-se importante o estudo para a proposição de métodos de tratamento de efluentes na indústria de laticínios, para a geração de efluentes de maior qualidade e que atendam aos padrões de lançamento previstos na legislação.

Os processos de separação por membranas têm ganhado destaque com relação ao tratamento de efluentes e a geração de águas de reúso. Em sistemas de separação por membranas são utilizadas membranas sintéticas, que imitam as características de seletividade das membranas naturais, no sentido de separar, concentrar ou purificar as substâncias presentes na água, tornando-a de melhor qualidade. Deve-se aplicar um gradiente de pressão hidráulica ou campo elétrico para que a separação ocorra (MIERZWA; HESPANHOL, 2005).

Um dos piores problemas citados pelos autores durante a operação dos sistemas de membranas é o decaimento do fluxo permeado com o tempo. Esse fenômeno é denominado de fouling ou colmatação da membrana (LAUTENSCHLAGER; FILHO; PEREIRA; 2009; HASAN, et al., 2013; GIACOBBO et al., 2010; SONG, 1998; VIDAL; CAMPOS; 2009).

Segundo Lautenschlager, Filho e Pereira (2009), a redução no fluxo permeado durante a filtração, aplicando-se pressão constante, ocorre devido à deposição de partículas coloidais e macromoléculas na superfície da membrana. Dessa forma, a limpeza da membrana deve ser realizada periodicamente durante a operação do sistema, para prevenir a possibilidade de colmatação extrema da membrana e até mesmo sua colmatação irreversível.

Os estudos utilizando os processos de separação por membranas tem variado muito, principalmente pela grande capacidade desse processo em concentrar, separar, purificar e tratar substâncias. $\mathrm{Na}$ área ambiental, principalmente nos últimos anos, houve diversos estudos utilizando as membranas, nos tratamentos de água, esgoto, efluentes industriais, entre outros.

O presente estudo consiste no tratamento de efluente de uma indústria de laticínios da região oeste do Estado do Paraná, por meio de membranas de microfiltração e ultrafiltração, verificando-se a eficiência do processo e o atendimento aos padrões de lançamento para esse tipo de efluente.

\section{MATERIAIS E MÉTODOS}

\section{COLETA DE AMOSTRAS NO SISTEMA DE TRATAMENTO DE EFLUENTES}

O efluente utilizado na presente pesquisa foi obtido em uma Unidade de Laticínios situada na região oeste do Estado do Paraná. Para os experimentos, foram realizadas coletas de 
3 lotes de amostras, os quais foram oriundos da estação de tratamento de efluentes da indústria, após o tratamento secundário (AATS).

Foram coletados em cada lote de amostra, 30 litros de efluente para a realização dos ensaios e das análises dos parâmetros físico-químicos e biológicos.

$\mathrm{Na}$ Tabela 1, tem-se os parâmetros físico-químicos que foram analisados e o método utilizado (APHA, 2012).

\section{Tabela 1 - Parâmetros para caracterização dos efluentes agroindustriais}

\begin{tabular}{ccc}
\hline Parâmetro & Unidade & $\begin{array}{c}\text { Método } \\
\text { (APHA, 2012) }\end{array}$ \\
\hline $\mathrm{pH}$ & - & $\begin{array}{c}\text { Potenciométrico } \\
4500-\mathrm{H}+\mathrm{B}\end{array}$ \\
Turbidez & $\mathrm{UNT}$ & $\begin{array}{c}\text { Nefelométrico } \\
2130 \mathrm{~B}\end{array}$ \\
Sólidos Totais & $\mathrm{mg} \mathrm{L}{ }^{-1}$ & $2540 \mathrm{~B}-$ \\
(ST) & & gravimétrico \\
Sólidos Totais & $\mathrm{mg} \mathrm{L}^{-1}$ & $2540 \mathrm{E}-$ \\
Fixos (STF) & & gravimétrico \\
Sólidos Totais & $\mathrm{mg} \mathrm{L}^{-1}$ & $2540 \mathrm{E}-$ \\
Voláteis (STV) & gravimétrico \\
Sólidos & & \\
Sedimentáveis & $\mathrm{mg} \mathrm{L}^{-1} \mathrm{~h}^{-1}$ & $2540 \mathrm{~F}$ \\
(SS) & &
\end{tabular}

Para a coleta de amostras foram seguidas as normas brasileiras NBR 9897 (planejamento de amostragem de efluentes líquidos e corpos receptores) e NBR 9898 (preservação e técnicas de amostragem de efluentes líquidos e corpos receptores) (ABNT, 1987a; ABNT, 1987b).

UNIDADE EXPERIMENTAL DE SEPARAÇÃO POR MEMBRANAS e CARACTERÍSTICAS DOS MÓDULOSDE MICROFILTRAÇÃO EULTRAFILTRAÇÃO

Os processos de separação por membranas foram realizados através de um módulo de bancada existente no Laboratório de Águas e Efluentes da Universidade Tecnológica Federal do Paraná (UTFPR - Câmpus Medianeira).

Os módulos utilizados no estudo foram de Microfiltração e Ultrafiltração (MF 158 e UF 257), adquiridos da Pam-membranas seletivas, mesma fabricante do módulo de bancada. Cada uma das membranas apresenta constituição e capacidade de retenção diferente. No Quadro 1 estão dispostas as informações das membranas de MF e UF, utilizadas durante o estudo (PAM MEMBRANAS, 2012). 


\section{Quadro 1 - Propriedades das membranas de microfiltração (MF 158) e de ultrafiltração (UF 257).}

\begin{tabular}{|c|c|c|c|}
\hline \multicolumn{2}{|c|}{ Microfiltração (158) } & \multicolumn{2}{|c|}{ Ultrafiltração (257) } \\
\hline Geometria & Tipo fibra oca & Geometria & Tipo fibra oca \\
\hline Material & $\begin{array}{l}\text { polieterimida } \\
(\mathrm{PEI})\end{array}$ & Material & $\begin{array}{l}\text { polietersulfona } \\
\text { (PES) }\end{array}$ \\
\hline Camada seletiva & Externa & Camada seletiva & Externa \\
\hline $\begin{array}{l}\text { Diâm. Externo } \\
(\mathrm{mm})\end{array}$ & 0,95 & $\begin{array}{l}\text { Diâm. Externo } \\
(\mathrm{mm})\end{array}$ & 0,70 \\
\hline $\begin{array}{l}\text { Tamanho de } \\
\text { poro }(\mu \mathrm{m})\end{array}$ & 0,40 & $\begin{array}{l}\text { Ret. Molar } \\
(\text { MWCO*) }\end{array}$ & 50 \\
\hline Limites de $\mathrm{Ph}$ & $2-13$ & Limites de $\mathrm{pH}$ & $2-13$ \\
\hline $\begin{array}{l}\text { Área de filtração } \\
\qquad\left(\mathrm{m}^{2}\right)\end{array}$ & 0,172 & $\begin{array}{l}\text { Área de filtração } \\
\qquad\left(\mathrm{m}^{2}\right)\end{array}$ & 0,09 \\
\hline $\begin{array}{l}\text { Densidade de } \\
\text { empacotamento } \\
\left(\mathrm{m}^{2} \cdot \mathrm{m}^{-3}\right)\end{array}$ & 800 & $\begin{array}{c}\text { Densidade de } \\
\text { empacotamento } \\
\left(\mathrm{m}^{2} \cdot \mathrm{m}^{-3}\right)\end{array}$ & 1000 \\
\hline $\begin{array}{c}\text { Permeabilidade } \\
\text { Hidráulica (L.h } \\
\left.{ }^{1} . \mathrm{m}^{2} . \mathrm{bar}\right)\end{array}$ & 99,7 & $\begin{array}{c}\text { Permeabilidade } \\
\text { Hidráulica (L.h } \\
\left.{ }^{1} . \mathrm{m}^{2} . \mathrm{bar}\right)\end{array}$ & 25,37 \\
\hline $\begin{array}{l}\text { Comprimento } \\
\text { útil (mm) }\end{array}$ & 350 & Rejeição (\%) & 99,91 \\
\hline $\begin{array}{c}\text { Temperatura } \\
\text { máxima de } \\
\text { Operação }\left({ }^{\circ} \mathrm{C}\right)\end{array}$ & 55 & $\begin{array}{c}\text { Temperatura } \\
\text { máxima de } \\
\text { Operação }\left({ }^{\circ} \mathrm{C}\right)\end{array}$ & 55 \\
\hline
\end{tabular}

* Molecular Weight Cutt-off (peso molecular de corte, tamanho das partículas retidas).

\section{EXPERIMENTOS DE FILTRAÇÃO POR MEMBRANAS}

Para cada ensaio, foram utilizados 5 litros de efluente oriundos do sistema de tratamento da indústria. Em todos os ensaios ocorreu o retorno do concentrado para o tanque de armazenamento, caracterizando um processo em batelada. A Tabela 2 apresenta as condições experimentais estabelecidas.

\section{Tabela 2 - Condições experimentais estabelecidas para os processos de separação} por membranas.

\begin{tabular}{cccc}
\hline Tratamento & Membrana & $\begin{array}{c}\text { Pressão } \\
\text { (Bar) }\end{array}$ & $\begin{array}{c}\text { Ponto de } \\
\text { coleta }\end{array}$ \\
\hline E1 & MF 158 & 0,50 & AATS \\
E2 & MF 158 & 0,75 & AATS \\
E3 & MF 158 & 1,0 & AATS \\
E4 & UF 257 & 0,50 & AATS \\
E5 & UF 257 & 1,0 & AATS \\
E6 & UF 257 & 1,5 & AATS \\
E7 & MF+UF & PMF+PUF & AATS \\
\hline
\end{tabular}

(MF 158 = Membrana Microfiltração série 158; UF 257 = Ultrafiltração série 257; PMF = Pressão para Microfiltração; PUF = Pressão para Ultrafiltração; AATS = Amostra Após Tratamento Secundário). 
Para os experimentos E1 a E6, utilizaram-se 3 pressões diferentes para cada membrana. Para a membrana de MF utilizaram-se as pressões de 0,5,0,75 e 1,0 bar. Para a membrana de UF as pressões utilizadas foram de 0,5,1,0 e 1,5 bar. As amostras de permeado foram coletadas para análise conforme fatores de concentração $(\mathrm{Fc})$ 1,25, 1,50,1,75,2,00 e 2,25, para os 6 tratamentos.

A partir dos 6 primeiros experimentos (E1 a E6) calculou-se o Índice de Qualidade do Permeado (IQP), definindo-se as melhores condições de pressão para a membrana de MF e para a de UF. Após a definição das melhores pressões, realizou-se o ensaio 7 e a microfiltração seguida da ultrafiltração (MF+UF). Nesse ensaio, coletou-se amostra somente no Fc 1,25.

As membranas foram avaliadas quanto aos parâmetros de processo:

Efeito da pressão - Pressão Transmembrana $(\Delta \mathrm{P})$;

Fluxo em função do tempo. O fluxo permeado $(\mathrm{J})$ foi determinado pela equação:

$\mathrm{J}=\mathrm{Vp} / \mathrm{A} \times \mathrm{t}$

Na equação 1, Vp é o volume permeado, A é a área de filtração da membrana e té o tempo.

Coeficiente de retenção ou rejeição que representa a eficiência do processo, o qual será calculado pela equação:

$\% \mathrm{R}=((\mathrm{Xf}-\mathrm{Xi}) / \mathrm{Xi}) \times 100$

Na equação 2, Xi é o valor inicial e Xf o valor final do parâmetro no permeado (por exemplo sólidos totais, sólidos sedimentáveis, etc);

Fator de Concentração $(\mathrm{Fc})$ pela equação:

$F_{c}=V_{i} /(V i-V p)$

Na equação 3, Fc é o Fator de concentração, Vi é o volume inicial de efluente utilizado e Vp corresponde ao volume permeado.

\section{ÍNDICE DE QUALIDADE DO PERMEADO (IQP)}

A definição das melhores condições de pressão para a MF e a UF foi realizada com auxílio de um Índice de Qualidade do Permeado (IQP), conforme Fappi (2015). Este índice engloba os parâmetros encontrados durante a caracterização das amostras (Tabela 1), após o sistema de tratamento por membranas, com amostras coletadas após o sistema de tratamento secundário da indústria (AATS). Os valores dos parâmetros para o cálculo deste índice foram obtidos nos experimentos E1 a E6 (Tabela 2).

Um valor maior para o parâmetro, significa menor qualidade. Foram atribuídos valores de mínimo e máximo, de 0 a 100 pontos, respectivamente, aos parâmetros e ao fluxo de permeado. Por exemplo, para o parâmetro sólidos totais, uma maior concentração de sólidos totais na amostra do 
permeado significa menor qualidade, atribuindo-se nota próxima a zero. Para uma concentração de sólidos totais menor, atribui-se uma nota maior (100). No caso do fluxo permeado, o oposto é realizado, sendo atribuída nota menor ao menor fluxo encontrado e nota maior para o maior fluxo, pois, nos processos de separação por membranas, maior fluxo é desejável.

Quanto maior a diferença entre os valores, maior a diferença entre os tratamentos. O IQP é obtido por meio do somatório dos valores atribuídos, no qual um índice de melhor qualidade refere-se ao que apresentar maior valor.

\section{LIMPEZA DAS MEMBRANAS}

Após os ensaios realizados com efluente de laticínio (Experimentos de 1 a 7 da Tabela 2), ocorreu a limpeza das membranas. A limpeza é realizada até que a membrana apresente o fluxo permeado encontrado nos ensaios de pressurização e despressurização das membranas de MF e UF, tolerando-se valores de fluxo inferiores ou superiores a $20 \%$, conforme orientações do fabricante das membranas. Utilizou-se os seguintes métodos para limpeza das membranas de MF e de UF (conforme recomendação do fabricante das membranas):

Lavagem da membrana no sentido contrário ao da filtração (retrolavagem), utilizando-se água microfiltrada gerada no próprio módulo, com inversão da entrada de água para a saída do permeado do módulo. A saída de concentrado é totalmente fechada através de plug, e a água que sai do módulo é descartada.

Limpeza através de produto químico, chamada de limpeza oxidante. Utiliza-se como oxidante o Hipoclorito de Sódio $\left(500 \mathrm{mg} \mathrm{L}^{-1}\right)$. Circula-se 1 litro da solução durante um período não superior a duas horas.

A retrolavagem é denominada de limpeza física das membranas, enquanto o segundo método denomina-se limpeza química. Após a utilização das membranas, a retrolavagem é realizada todas as vezes para a limpeza das membranas.

A limpeza química é utilizada somente quando não se restabelece o fluxo das membranas de MF e UF por meio da limpeza física. A limpeza química é mais agressiva e pode danificar os componentes da membrana caso não seja realizada conforme informado pelo fabricante.

\section{RESULTADOS E DISCUSSÃO}

\section{CARACTERÍSTICAS DAS AMOSTRAS DE EFLUENTES COLETADAS}

De acordo com os dados disponibilizados pela indústria pesquisada, a estação de tratamento de efluentes (ETE) é responsável pelo tratamento de todo o efluente gerado nos setores industriais.

Durante a realização da pesquisa, a indústria estava modificando seu sistema de tratamento de efluentes e realizando adaptações para aumentar a estrutura produtiva, o que implicou na coleta de lotes de amostras de efluentes com diferenças em suas características físico-químicas.

$\mathrm{Na}$ Figura 1, pode ser observada a característica visual das amostras coletadas no sistema de tratamento de efluentes em cones Imhoff, durante a realização das análises de Sólidos Sedimentáveis. 
Figura 1 - Amostra de efluente após lagoa aerada (AATS).

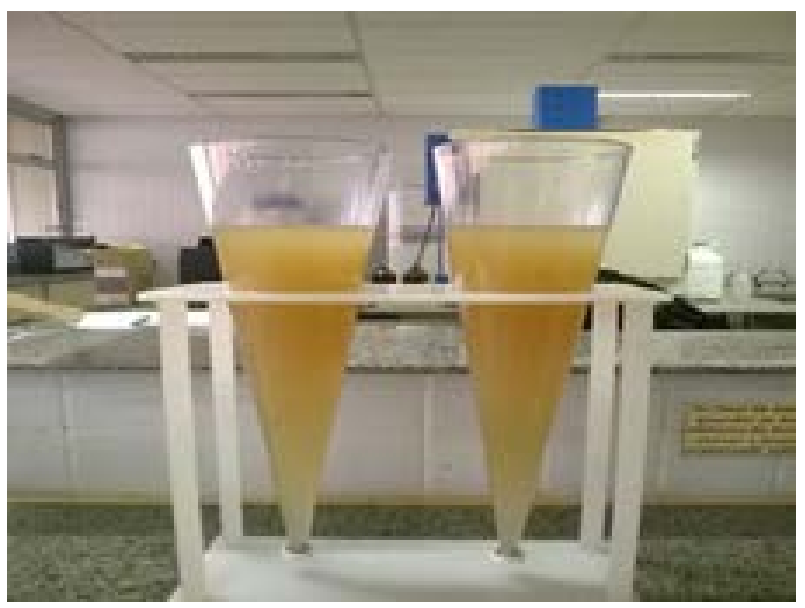

$\mathrm{Na}$ Tabela 3 estão dispostas as características das 3 amostras coletadas no sistema de tratamento de efluentes da indústria de laticínio (AATS).

Tabela 3 - Características qualitativas das amostras de efluente utilizadas nos ensaios.

\begin{tabular}{|c|c|c|c|}
\hline Parâmetro & $\begin{array}{l}\text { Efluente } \\
\text { (Lote 1) }\end{array}$ & $\begin{array}{l}\text { Efluente } \\
\text { (Lote 2) }\end{array}$ & $\begin{array}{l}\text { Efluente } \\
\text { (Lote 3) }\end{array}$ \\
\hline Data da Coleta & $5 / 10 / 15$ & $7 / 10 / 15$ & $13 / 11 / 15$ \\
\hline $\begin{array}{l}\text { Temperatura de } \\
\text { Coleta }\left({ }^{\circ} \mathrm{C}\right)\end{array}$ & 27 & 27 & 23,5 \\
\hline $\begin{array}{l}\text { Sólidos Totais (mg } \\
\left.\mathrm{L}^{-1}\right)\end{array}$ & $2.876,50$ & 3.484 & 2.622 \\
\hline $\begin{array}{l}\text { Sólidos Totais } \\
\text { Fixos }\left(\mathrm{mg} \mathrm{L}^{-1}\right)\end{array}$ & $1.841,50$ & 1.953 & 1.795 \\
\hline $\begin{array}{l}\text { Sólidos Totais } \\
\text { Voláteis }\left(\mathrm{mg} \mathrm{L}^{-1}\right)\end{array}$ & 1.035 & 1.531 & 827 \\
\hline $\mathrm{Ph}$ & 8,55 & 8,52 & 8,83 \\
\hline Turbidez (NTU) & 673 & 595 & 441 \\
\hline $\begin{array}{l}\text { Sólidos } \\
\text { Sedimentáveis } \\
\left(\mathrm{mL} \mathrm{L}^{-1} \mathrm{~h}^{-1}\right)\end{array}$ & $<0,1$ & $<0,1$ & 0,2 \\
\hline $\mathrm{DBO}\left(\mathrm{mg} \mathrm{L}^{-1}\right)$ & $\mathrm{NR}^{*}$ & $\mathrm{NR}^{*}$ & 467 \\
\hline DQO $\left(\mathrm{mg} \mathrm{L}^{-1}\right)$ & $\mathrm{NR}^{*}$ & $\mathrm{NR}^{*}$ & 894 \\
\hline
\end{tabular}

*NR = Análise não realizada.

De acordo com os dados dispostos na Tabela 3, as características físico-químicas dos lotes de efluente apresentaram variação. Especificamente as concentrações de sólidos no efluente, podem ter influenciado os fenômenos de fouling das membranas de MF e UF. 
Para os 6 ensaios (E1 a E6) foram realizados menor número de análises de parâmetros (SS, ST, STF, STV, pH e Turbidez), pois tais ensaios foram utilizados para estabelecer as melhores condições de pressão para as membranas de MF e UF, e um maior número de análises tornaria a pesquisa onerosa.

\section{COMPORTAMENTO DO FLUXO PERMEADO PARA MEMBRANA DE MICROFILTRAÇÃO}

Os ensaios E1, E2 e E3, dos experimentos propostos (Tabela 2) foram realizados com a membrana de MF, nas pressões de 0,5,0,75 e 1,0 bar. O efluente do Lote 1 foi utilizado para a realização dos ensaios. O comportamento do fluxo permeado, nas três pressões, com as amostras de efluente coletadas após o tratamento secundário da indústria de laticínios (AATS) é apresentado na Figura 2.

\section{Figura 2 - Comportamento do fluxo permeado na membrana de microfiltração (MF 158) nas pressões 0,5, 0,75 e 1,0 bar com efluente de laticínio.}

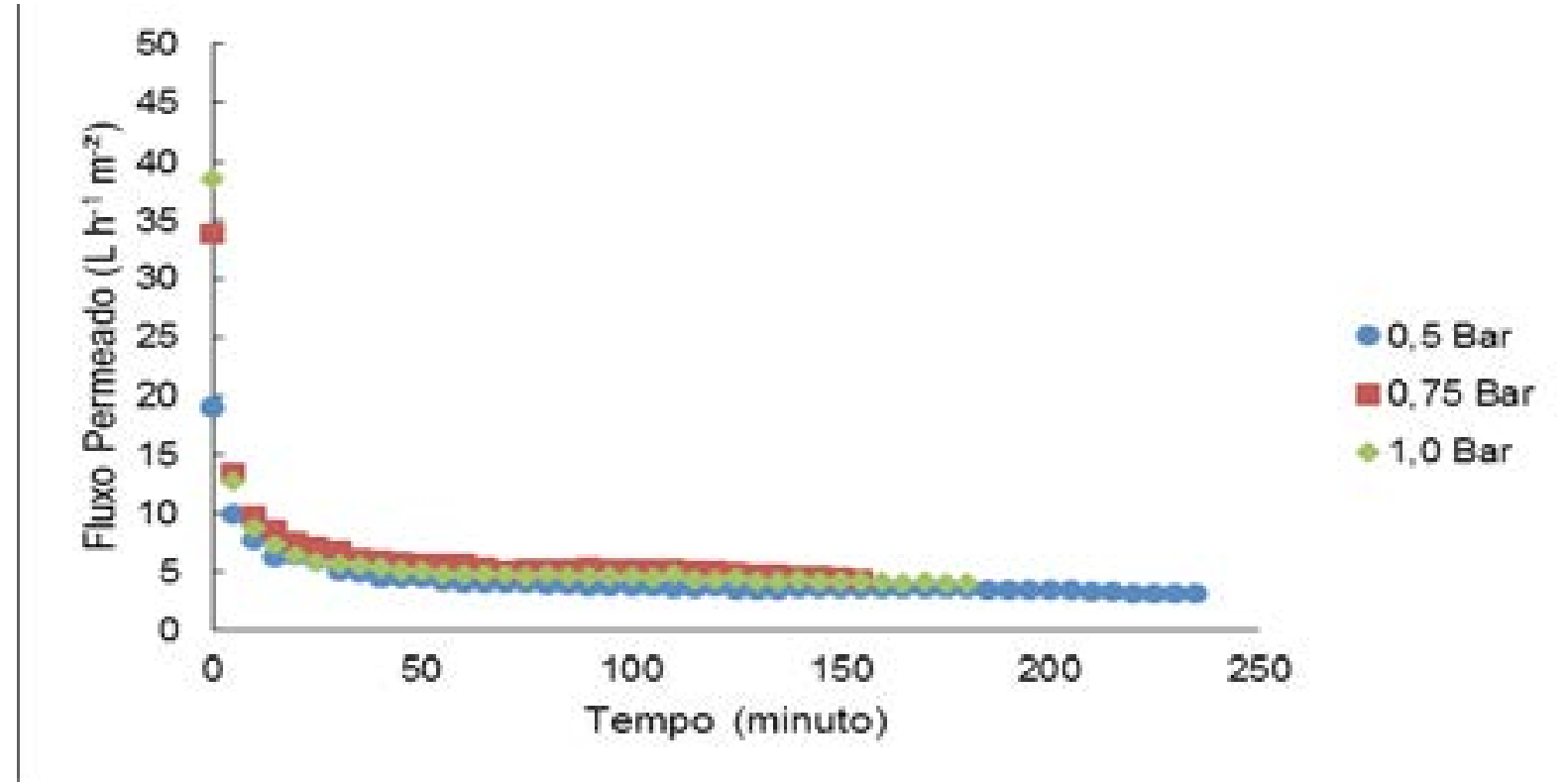

Os dados dispostos na Figura 2 demonstram que, com o aumento da pressão, o fluxo permeado inicial ( Ji) também aumentou. Entretanto, houve grande queda do fluxo permeado nos primeiros minutos de operação, para as 3 pressões $(47,98,60,14$ e $66,83 \%$, para as pressões de 0,5, 0,75 e 1,0 bar, respectivamente). A partir de 60 minutos, aproximadamente, ocorreu a estabilização do fluxo permeado em 4,11, 5,62 e 4,81 $\mathrm{L} \mathrm{h}^{-1} \mathrm{~m}^{-2}$ bar $^{-1}$, para as pressões de 0,5, 0,75 e 1,0 bar, respectivamente.

O fluxo não apresentou linearidade com o aumento da pressão, como pode ser visto através da Figura 2, o que indica, de acordo com Habert, Borges e Nobrega (2006) que pode haver transformação na estrutura dos poros da membrana, bem como acúmulo de substâncias em sua superfície. Acero et al. (2010) cita que a não linearidade do fluxo permeado, com o aumento da pressão, indica o acúmulo de partículas na superfície da membrana. 
Em processos de separação por membranas de MF e UF, o comportamento do fluxo permeado, de acordo com Song (1998) é composto por 3 estágios. O estágio 1 é caracterizado por um rápido declínio do fluxo de filtração; seguido por um longo decréscimo do fluxo (estágio 2), finalizando com a estabilização do fluxo permeado (estágio 3). A autora explica que o estágio 2 ocorre em todos os processos de fouling das membranas, independentemente das condições de operação. Os estágios 1 e 3 podem não ocorrer por vários motivos, especificamente porque a estabilização do fluxo precisa de um longo tempo de operação para ocorrer.

A redução do fluxo permeado no decorrer do tempo de filtração, gera uma curva característica de processos de separação por membranas, em especial, utilizando-se membranas de microfiltração e ultrafiltração. A variação típica do fluxo da membrana em relação ao tempo refere-se ao rápido decréscimo inicial do fluxo de permeado, seguido de um longo e gradual período onde há também o declínio do fluxo (FIELD et al., 1995).

Segundo Lautenschlager, Filho e Pereira (2009) e Bullón et al. (2007), a causa da redução do fluxo permeado é o acúmulo de substâncias na superfície da membrana. Além disso, essa curva característica é encontrada em diversos estudos, podendo-se citar Acero et al. (2010), Amaral et al. (2013) e Brião e Tavares (2007), por exemplo.

Os fluxos iniciais da membrana de MF para as pressões de 0,5, 0,75 e 1,0 bar foram de $19,07,33,95$ e $38,69 \mathrm{~L} \mathrm{~h}^{-1} \mathrm{~m}^{-2}$, respectivamente. Com 150 minutos de ensaio, os fluxos permeados para as pressões de 0,5, 0,75 e 1,0 bar diminuíram para 3,58, 4,52 e 4,22 $\mathrm{L} \mathrm{h}^{-1} \mathrm{~m}^{-2}, 81,23,86,68$ e $89,10 \%$ de redução do fluxo, respectivamente.

A membrana de MF para a pressão de 1,0 bar teve maior queda do fluxo se comparada com as pressões de 0,5 e 0,75 bar, o que pode estar associado à compactação dos poros, segundo Sarmento (2007), bem como aos fenômenos de incrustação, concentração de polarização e colmatação da membrana, citados por Schneider e Tsutyia (2001).

Nos primeiros cinco minutos, ocorreu elevada queda do fluxo permeado para as três pressões, de 47,98,60,14 e 66,83\%, para as pressões de 0,5, 0,75 e 1,0 bar, respectivamente. Após os 60 minutos o fluxo caiu mais de $80 \%$ para as três pressões.

Considerando-se o fluxo médio a partir dos 60 minutos para a três pressões, o maior fluxo permeado encontrado foi na pressão de 0,75 bar. Os fluxos médios para as pressões de $0,5,0,75$ e 1,0 bar foram de 3,79,5,14 e 4,51 $\mathrm{L} \mathrm{h}^{-1} \mathrm{~m}^{-2}$, respectivamente.

Para uma membrana polimérica com dimensão de poro de $0,1 \mu \mathrm{m}$ e material de produção poliamida, aplicando pressão transmembrana de 2,0 bar no tratamento de água produzida de petróleo, Weschenfelder, Borges e Campos (2015) também encontraram queda considerável do fluxo permeado ao final do experimento (60\%).

\section{COMPORTAMENTO DO FLUXO PERMEADO PARA MEMBRANA DE ULTRAFILTRAÇÃO}

Para a membrana de UF, a Figura 3 demonstra o comportamento do fluxo permeado nos três ensaios (E4, E5 e E6) com as amostras de efluente coletadas após o tratamento secundário da indústria de laticínios (Lote 2, Tabela 3).

Optou-se por utilizar maiores pressões para a membrana de ultrafiltração, pois, para esse tipo de membrana, há maior amplitude na utilização da força motriz (SCHNEIDER; TSUTYIA, 2001; HABERT; BORGES; NOBREGA, 2006). 
A curva característica do fluxo permeado no decorrer dos ensaios também ficou evidente para a membrana de UF, havendo grande queda no fluxo permeado nos primeiros minutos e posterior estabilização após 60 minutos (Figura 3).

Figura 3 - Comportamento do fluxo permeado na membrana de microfiltração (MF 158) nas pressões 0,5, 0,75 e 1,0 bar com efluente de laticínio.

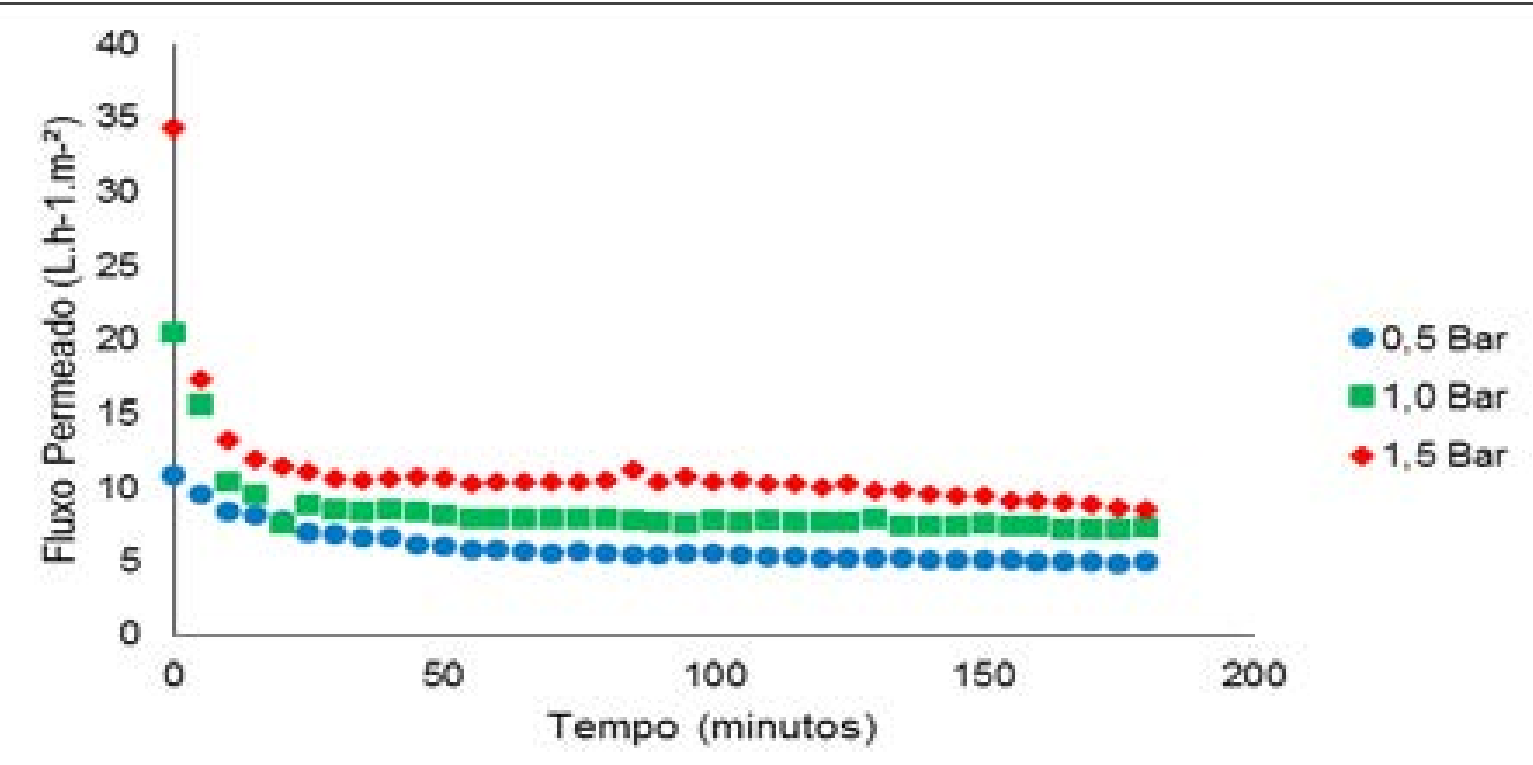

Após o período de 60 minutos, semelhante à membrana de MF, para a membrana de UF também há estabilização no fluxo permeado. As pressões mais altas apresentaram fluxo maior no decorrer do tempo, para a membrana de ultrafiltração.

Os autores Brião e Tavares (2007), ao estudarem dois tipos de membranas de ultrafiltração no tratamento de efluentes de laticínio, também encontraram rápido declínio do fluxo permeado nos primeiros minutos da operação do sistema.

Nos primeiros cinco minutos ocorreu queda considerável do fluxo permeado, de 11,36, 23,68 e 49,50\% para as pressões de 0,5,1,0 e 1,5 bar, respectivamente. Após os 60 minutos, o fluxo caiu mais de $60 \%$ para as pressões de 1,0 e 1,5 bar. Para as pressões de $0,5,1,0$ e 1,5 bar, ao final do ensaio ocorreu redução no fluxo de 53,24, 63,00 e 72,48\%, respectivamente.

O maior fluxo médio, a partir dos 60 minutos para a três pressões utilizadas, foi determinado para a pressão de 1,5 bar. Os fluxos médios para as pressões de 0,5,1,0 e 1,5 bar foram de 5,42, 7,72 e $10,11 \mathrm{~L} \mathrm{~h}^{-1} \mathrm{~m}^{-2}$, respectivamente.

Se comparado o fluxo da membrana de UF com o da membrana de MF, verifica-se que o fluxo permeado foi mais elevado para a UF. Esse fato pode ser explicado, pelo maior efeito de colmatação e entupimento dos poros apresentado pela membrana de microfiltração, que influencia diretamente na queda do fluxo. Fappi (2015) encontrou condições contrárias para o fluxo permeado, estudando membranas de MF e UF semelhantes às utilizadas no presente trabalho, no tratamento de efluente de matadouro frigorífico. $\mathrm{O}$ autor citado encontrou maiores fluxos permeados para a membrana de microfiltração em comparação com as de ultrafiltração que utilizou no estudo. Isso pode ser atribuído à diferença nas características do efluente, sendo que as partículas presentes no efluente de laticínio contribuem mais para a colmatação da membrana de MF. 
No mesmo sentido, Schmitt et al. (2013) utilizaram uma membrana de UF de cerâmica, com diâmetro de poro de $0,1 \mu \mathrm{m}$ e retenção molar de $4 \mathrm{kDa}$, no tratamento de efluente oriundo de processo de limpeza de pasteurizadores de uma indústria de laticínios. Também encontraram considerável queda no fluxo permeado no decorrer do estudo, próximo de $80 \%$, utilizando pressão transmembrana de 2 bar.

O aspecto visual das amostras de permeado coletadas após os tratamentos por membranas de microfiltração (MF 158) e ultrafiltração (UF 257) está disposto na Figura 4.

\section{Figura 4 - Aspecto visual das amostras de permeado de MF 158 (A) e UF 257 (B).}

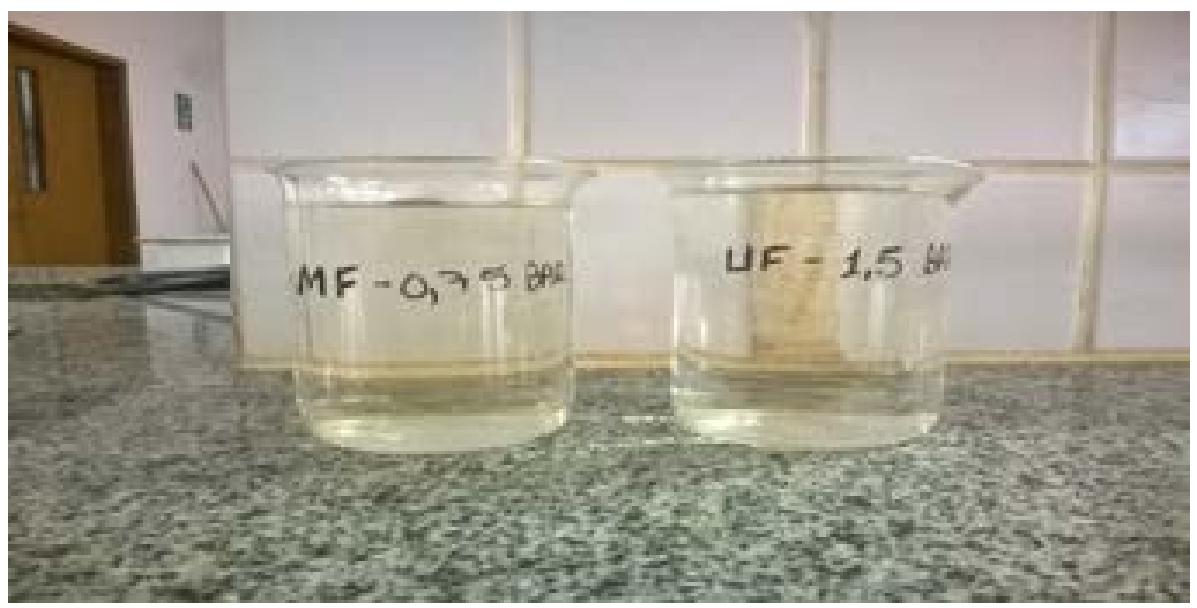

\section{EFICIÊNCIA DO SISTEMA DE TRATAMENTO DE MICROFILTRAÇÃO EM RELAÇÃO AOS FATORES DE CONCENTRAÇÃO}

Para os 3 primeiros tratamentos utilizando as 3 pressões para a membrana de $\mathrm{MF}$, foram coletadas amostras nos fatores de concentração 1,25, 1,5, 1,75, 2,0 e 2,25. Foram analisados os parâmetros sólidos totais, sólidos totais fixos, sólidos totais voláteis, $\mathrm{pH}$, turbidez e sólidos sedimentáveis.

É relevante o monitoramento dos sólidos no efluente, pois são responsáveis pela colmatação das membranas e reduzem o fluxo que é permeado por elas, muitas vezes inviabilizando o processo.

Para todos os ensaios em todos os fatores de concentração ocorreu remoção de $100 \%$ tanto da Turbidez, quanto dos Sólidos Sedimentáveis. Os dados encontrados após os tratamentos e a eficiência do tratamento, por pressão utilizada e por fator de concentração, estão dispostos na Tabela 4. 
Tabela 4 - Resultados por fator de concentração e eficiência do processo para a membrana de MF 0,5, 0,75 e 1,0 bar.

\begin{tabular}{|c|c|c|c|c|c|c|c|c|c|c|c|}
\hline \multirow[t]{2}{*}{ Pressão } & \multirow[t]{2}{*}{ Parâmetro } & \multicolumn{10}{|c|}{$\begin{array}{c}\text { Concentração por Fatores de Concentração }(\mathrm{Fc}) \text { e eficiência do } \\
\text { tratamento }(\mathrm{E})\end{array}$} \\
\hline & & 1,25 & $\mathrm{E}(\%)$ & 1,50 & $\mathrm{E}(\%)$ & 1,75 & $\mathrm{E}(\%)$ & 2,00 & $\mathrm{E}(\%)$ & 2,25 & E (\%) \\
\hline \multirow{4}{*}{0,5 bar } & $S T\left(m g L^{-1}\right)$ & 1.662 & 42,22 & 1.243 & 56,79 & 1.901 & 33,91 & 2.015 & 29,95 & 2.075 & 27,86 \\
\hline & $\operatorname{STF}\left(m g L^{-1}\right)$ & 1.391 & 24,46 & 1.049 & 43,04 & 1.605 & 12,84 & 1.785 & 3,07 & 1.789 & 2,85 \\
\hline & $\operatorname{STV}\left(\mathrm{mg} \mathrm{L}^{-1}\right)$ & 271 & 73,82 & 194 & 81,26 & 296 & 71,40 & 230 & 77,78 & 223 & 78,45 \\
\hline & \multirow[t]{2}{*}{$\mathbf{P h}$} & 8,76 & - & 9,05 & - & 9,27 & - & 9,31 & - & 9,31 & - \\
\hline & & 1,25 & E (\%) & 1,50 & E (\%) & 1,75 & E (\%) & 2,00 & E (\%) & 2,25 & E (\%) \\
\hline \multirow{4}{*}{0,75 bar } & $\mathrm{ST}\left(\mathrm{mg} \mathrm{L}^{-1}\right)$ & 1.996 & 30,61 & 2.330 & 19,00 & 1.747 & 39,27 & 1.753 & 39,06 & 1.566 & 45,56 \\
\hline & $\operatorname{STF}\left(\mathrm{mg} \mathrm{L}^{-1}\right)$ & 1.730 & 6,05 & 1.704 & 7,47 & 1.258 & 31,69 & 1.404 & 23,76 & 1.473 & 20,01 \\
\hline & $\operatorname{STV}\left(\mathbf{m g ~ L}^{-1}\right)$ & 266 & 74,30 & 426 & 58,84 & 489 & 52,75 & 349 & 66,28 & 93 & 91,01 \\
\hline & \multirow[t]{2}{*}{ pH } & 8,04 & - & 8,21 & - & 8,39 & - & 8,49 & - & 8,50 & - \\
\hline & & 1,25 & E (\%) & 1,50 & E (\%) & 1,75 & E (\%) & 2,00 & E (\%) & 2,25 & E (\%) \\
\hline \multirow{4}{*}{ 1,0 bar } & $\mathrm{ST}\left(\mathrm{mg} \mathrm{L}^{-1}\right)$ & 1.837 & 36,14 & 1.562 & 45,70 & 1.819 & 36,76 & 1.590 & 44,72 & 1.845 & 35,86 \\
\hline & STF $\left(\mathrm{mg} \mathrm{L}^{-1}\right)$ & 1.563 & 15,12 & 1.345 & 26,96 & 1.456 & 20,93 & 1.181 & 35,87 & 1.508 & 18,11 \\
\hline & $\operatorname{STV}\left(\mathrm{mg} \mathrm{L}^{-1}\right)$ & 274 & 73,53 & 217 & 79,03 & 363 & 64,93 & 409 & 60,48 & 337 & 67,44 \\
\hline & $\mathrm{pH}$ & 8,09 & - & 8,2 & - & 8,52 & - & 8,43 & - & 8,47 & - \\
\hline
\end{tabular}

Neta, Habert e Borges (2005), encontraram para a microfiltração de cerveja, valores altos de remoção da turbidez, chegando a $98 \%$ de eficiência, utilizando membrana de microfiltração $(0,4$ $\mu \mathrm{m})$, semelhante à utilizada na presente pesquisa. A remoção da turbidez tem grande importância, pois influencia no aspecto visual do efluente, tornando o efluente mais aceitável quando há menor turbidez.

A eficiência de retenção de sólidos totais foi mais alta para o fator de concentração de 1,5, nas pressões de 0,5 e 1,0 bar, condição oposta visualizada para a pressão de 0,75 bar. Para os três últimos fatores de concentração, houve diminuição na eficiência, sendo semelhante às eficiências encontradas para os três fatores de concentração.

O comportamento para a retenção de sólidos totais fixos foi menos eficiente se comparada com a retenção de sólidos totais voláteis. Para a pressão de 0,5 bar, ocorreu queda considerável na eficiência de retenção dos sólidos totais fixos nos fatores de concentração de 1,75, 2,00 e 2,25, sendo que a eficiência para os dois últimos fatores de concentração foi de 3,07 e 2,85\%, respectivamente, demonstrando que houve passagem dos sólidos totais fixos pela membrana.

A retenção de sólidos totais voláteis foi mais eficiente na membrana de MF, para as diferentes pressões, comparando-se com os totais fixos. A eficiência chegou a mais de $90 \%$ para a pressão de 0,75 bar, no fator de concentração de 2,25.

As diferentes eficiências apresentadas pelas membranas nas diferentes pressões e nos diferentes fatores de concentração, demonstram que a concentração do efluente a ser tratado pode influenciar a eficiência da membrana, além de ser possível visualizar que a retenção de sólidos totais, sólidos totais fixos e sólidos totais voláteis não é constante. 


\section{EFICIÊNCIA DO SISTEMA DE TRATAMENTO DE ULTRAFILTRAÇÃO EM RELAÇÃO AOS FATORES DE CONCENTRAÇÃO}

Para a membrana de UF foram coletadas amostras em menor número de fatores de concentração, pois a área de filtração do módulo é bastante inferior ao de microfiltração, precisando de tempos muito longos para atingir os fatores de concentração estipulados.

Os valores após os tratamentos e a eficiência, por pressão utilizada e por fator de concentração, estão dispostos na Tabelas 5. A eficiência foi calculada para cada fator de concentração, utilizando o valor do parâmetro encontrado no efluente Lote 2 (Tabela 3) e a concentração encontrada no permeado após a UF.

\section{Tabela 5 - Resultados por fator de concentração $(\mathrm{Fc})$ e eficiência do processo (\%) para a membrana de UF 0,5, 1,0 e 1,5 bar.}

\begin{tabular}{|c|c|c|c|c|c|c|c|c|c|}
\hline Pressão & Parâmetro & 1,25 & E (\%) & 1,50 & E (\%) & - & - & - & - \\
\hline \multirow{5}{*}{0,5 bar } & $\mathrm{ST}(\mathrm{mg} \mathrm{L})$ & 1.924 & 44,78 & 1.811 & 48,02 & - & - & - & - \\
\hline & STF (mg L) & 1.608 & 17,67 & 1.517 & 22,32 & - & - & - & - \\
\hline & STV (mg L) & 316 & 79,36 & 294 & 80,80 & - & - & - & - \\
\hline & $\mathrm{pH}$ & 8,89 & - & 9,00 & - & - & - & - & - \\
\hline & & 1,25 & E (\%) & 1,50 & E (\%) & 1,75 & E (\%) & 2,00 & E (\%) \\
\hline \multirow{5}{*}{1,0 bar } & $\mathrm{ST}(\mathrm{mg} \mathrm{L})$ & 2.002 & 42,54 & 1.889 & 45,78 & 1.976 & 43,28 & 1.574 & 54,82 \\
\hline & STF (mg L) & 1.879 & 3,79 & 1.786 & 8,55 & 1.857 & 4,92 & 1.285 & 34,20 \\
\hline & $\mathrm{STV}(\mathrm{mg} \mathrm{L})$ & 123 & 91,97 & 103 & 93,27 & 119 & 92,23 & 289 & 81,12 \\
\hline & $\mathrm{pH}$ & 8,76 & - & 8,89 & - & 9,00 & - & 9,00 & - \\
\hline & & 1,25 & E (\%) & 1,50 & E (\%) & 1,75 & E (\%) & 2,00 & E (\%) \\
\hline \multirow{4}{*}{$1,5 \mathrm{bar}$} & ST (mg L) & 1784 & 48,79 & 1812 & 47,99 & 1857 & 46,70 & 1861 & 46,58 \\
\hline & $\mathrm{STF}(\mathrm{mg} \mathrm{L})$ & 1601 & 18,02 & 1599 & 18,13 & 1658 & 15,10 & 1674 & 14,29 \\
\hline & STV (mg L) & 183 & 88,05 & 213 & 86,09 & 199 & 87,00 & 187 & 87,79 \\
\hline & $\mathrm{pH}$ & 8,84 & - & 8,89 & - & 9 & - & 9 & - \\
\hline
\end{tabular}

A membrana de UF apresentou eficiência de $100 \%$ na remoção da Turbidez nas três pressões e nos diferentes fatores de concentração, mesmo com a elevada Turbidez encontrada no Efluente de laticínio do Lote 2 (Tabela 3).

Os dados referentes à retenção dos sólidos pela membrana de UF demonstraram eficiência mais constante por parte da membrana de UF, especialmente para os Sólidos Totais, na faixa de remoção de 42,54-54,82\%, e Sólidos Totais Voláteis, na faixa de 79,36 - 93,27\%. Isso demonstra menor efeito da concentração do efluente na eficiência da membrana.

Foram encontradas maiores eficiências de retenção de sólidos voláteis, nos diferentes fatores de concentração, para a membrana de UF. As eficiências foram maiores para as pressões de 1,0 e 1,5 bar, variando entre 80 e $90 \%$ para os fatores de concentração $(1,25,1,5,1,75$ e 2,00).

A membrana de UF apresentou menor eficiência na retenção dos sólidos totais fixos. Para a pressão de 1,0 bar, as eficiências para os 3 primeiros fatores de concentração $(1,25,1,5$ e 1,75) foram de apenas $3,79,8,55$ e 4,92\%, respectivamente. A eficiência de remoção mais alta foi na pressão de 1,0 bar, no fator de concentração 2,0 (34,20\%). 


\section{CÁLCULO DO ÍNDICE DE QUALIDADE DO PERMEADO (IQP)}

O Índice de Qualidade do Permeado (IQP) foi calculado com o objetivo de definir a melhor condição de pressão para as membranas de MF e de UF, para utilização no ensaio 7 (MF+UF). No cálculo do índice entraram como parâmetros: Sólidos Totais, Sólidos Totais Fixos, Sólidos Totais Voláteis, Sólidos Sedimentáveis, Turbidez e fluxo permeado médio (para os fatores de concentração $1,25,1,50,1,75,2,00$ e 2,25 na membrana de MF e 1,25 e 1,5 para a membrana de UF).

Para cada parâmetro foram atribuídos valores, sendo o menor valor encontrado para o parâmetro, igual a 100 pontos e o maior valor igual a 0 pontos. Os valores intermediários receberam valores relativos ao percentual entre a diferença do valor máximo e mínimo. Para o parâmetro fluxo permeado médio ocorreu o contrário, atribuindo-se menor valor para o menor fluxo e maior valor para o maior fluxo, pois, nos processos de separação por membranas, um fluxo alto é desejável.

Para o cálculo do Índice de Qualidade do Permeado (IQP), considerou-se o exposto por Fappi (2015). Para cada fator de concentração, somaram-se os valores de qualidade atribuídos aos parâmetros, chegando-se a um valor final, o IQP.

ÍNDICE DE QUALIDADE DO PERMEADO PARA A MEMBRANA DE MICROFILTRAÇÃO E DE ULTRAFILTRAÇÃO

Os índices de qualidade encontrados para as membranas de microfiltração e ultrafiltração, para os diferentes fatores de concentração, estão expostos na Tabela 6. Os melhores índices foram destacados na Tabela com um asterisco (*).

Durante a execução dos três ensaios para a membrana de UF (E4, E5 e E6), optou-se por diminuir os fatores de concentração. Assim, para a definição do IQP, utilizaram-se os fatores de 1,25 e 1,5 apenas, pois, foram realizadas coletas de amostra em tais fatores de concentração para as três pressões. 
Tabela 6 - Índice de qualidade do permeado, por pressão e fator de concentração para a membrana de MF.

\begin{tabular}{|c|c|c|c|}
\hline Membrana & Pressão & $\begin{array}{c}\text { Fator de } \\
\text { Concentração }\end{array}$ & IQP \\
\hline \multirow{15}{*}{ MF 158} & \multirow{3}{*}{0,5} & 1,25 & 362 \\
\hline & & 1,50 & $600^{*}$ \\
\hline & & 1,75 & 300 \\
\hline & \multirow{2}{*}{0,5} & 2,00 & 300 \\
\hline & & 1,25 & 247 \\
\hline & \multirow{5}{*}{0,75} & 1,25 & $500^{*}$ \\
\hline & & 1,50 & 400 \\
\hline & & 1,75 & $600^{*}$ \\
\hline & & 2,00 & 506 \\
\hline & & 2,25 & $696^{*}$ \\
\hline & \multirow{5}{*}{1} & 1,25 & 489 \\
\hline & & 1,50 & 559 \\
\hline & & 1,75 & 448 \\
\hline & & 2,00 & $594^{*}$ \\
\hline & & 2,25 & 530 \\
\hline \multirow{6}{*}{ UF 257} & \multirow{2}{*}{0,5} & 1,25 & 234 \\
\hline & & 1,5 & 487 \\
\hline & \multirow{2}{*}{1} & 1,25 & 444 \\
\hline & & 1,5 & 444 \\
\hline & \multirow{2}{*}{1,5} & 1,25 & $630^{*}$ \\
\hline & & 1,5 & $500^{*}$ \\
\hline
\end{tabular}

(*) Maiores valores de IQP nas diferentes pressões e fatores de concentração.

Na pressão de 0,75 bar a membrana de MF apresentou os melhores IQPs para os fatores de concentração de 1,25, 1,75 e 2,25. Nas demais pressões, apenas um dos fatores de concentração (1,5 para a pressão de 0,5 bar e 2,0 para a pressão de 1,0 bar) apresentou maior qualidade. Desta forma, através do IQP, a pressão de 0,75 bar foi escolhida como a melhor pressão de operação para a membrana de MF.

Para a membrana de UF, para os dois fatores de concentração, a pressão de 1,5 bar mostrou-se mais adequada, atingindo o maior IQP. Nesse sentido, essa pressão foi considerada a melhor operação para a membrana.

ENSAIOS DE MICROFILTRAÇÃO SEGUIDA DE ULTRAFILTRAÇÃO (MF+UF)

$\mathrm{O}$ ensaio $\mathrm{E} 7$ foi realizado com a melhor condição de pressão para a membrana de $\mathrm{MF}$ (0,75 bar) e da membrana de UF (1,5 bar), utilizando o efluente do Lote 3.

No ensaio de MF, utilizou-se uma quantidade maior de efluente (10 litros), devido a necessidade de permeação de 5 litros para utilização posterior na UF. Foi coletada amostra no fator de concentração de 1,25 para as duas membranas.

$\mathrm{Na}$ Figura 5, para o ensaio de microfiltração, o tempo de permeação foi bastante extenso até que houvesse a coleta de 5 litros de amostra a ser utilizada durante a UF. Para um tempo 
maior de filtração, foi possível verificar os 3 estágios citados por Song (1998): rápido decaimento do fluxo (estágio 1), seguido de longo decaimento do fluxo (estágio 2) e posterior estabilização do fluxo permeado (estágio 3).

Figura 5 - Fluxo permeado para a membrana de MF, pressão 0,75 bar, durante os ensaios de MF+UF (E7).

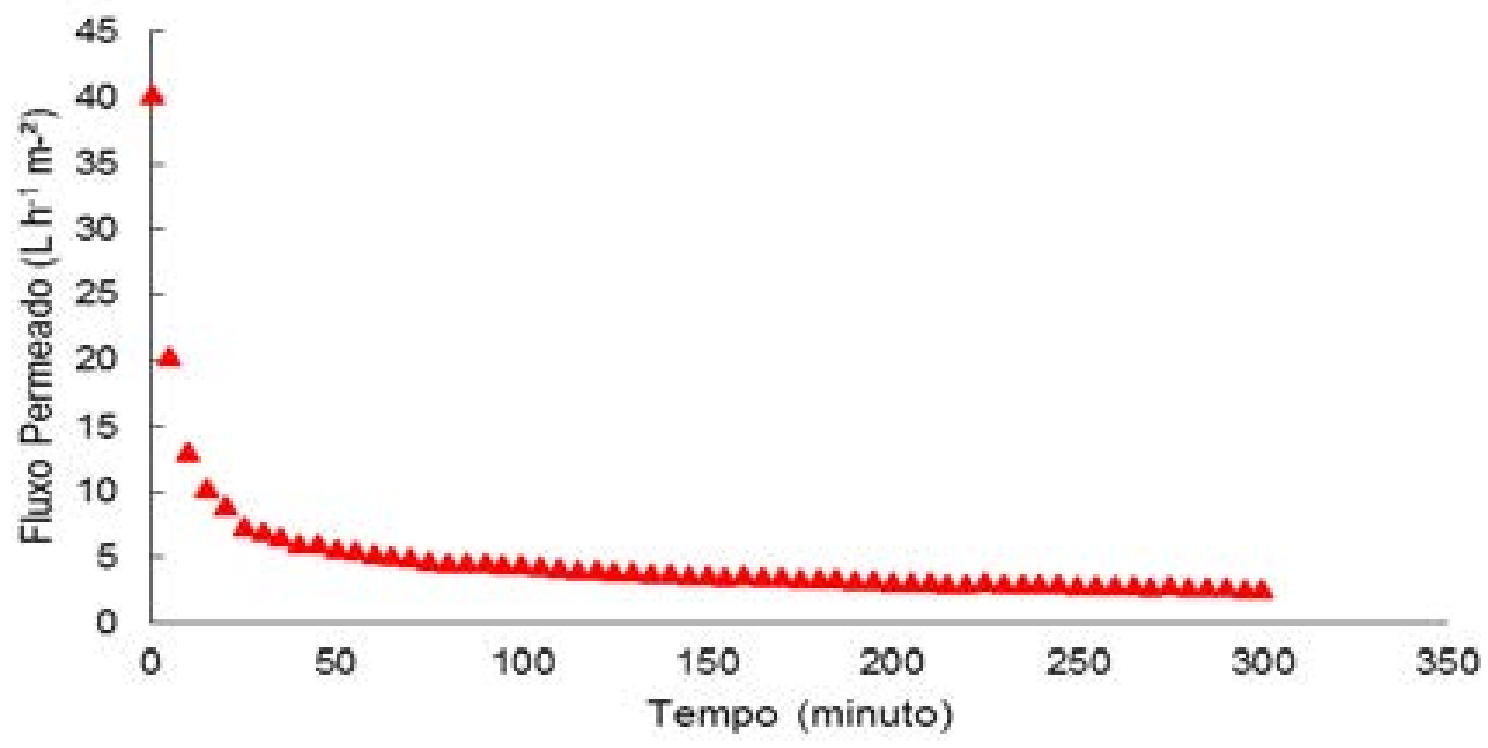

O comportomento do fluxo permeado no decorrer do tempo durante a UF, a partir do permeado da MF, foi bastante diferente dos demais ensaios realizadas. Na Figura 6, verifica-se que não houve decaimento inicial do fluxo permeado para a membrana de UF. Esse fato pode estar associado a menor concentração de sólidos no permeado da MF.

Figura 6 - Fluxo permeado para a membrana de UF, pressão 1,5 bar, durante os ensaios de MF+UF (T9).

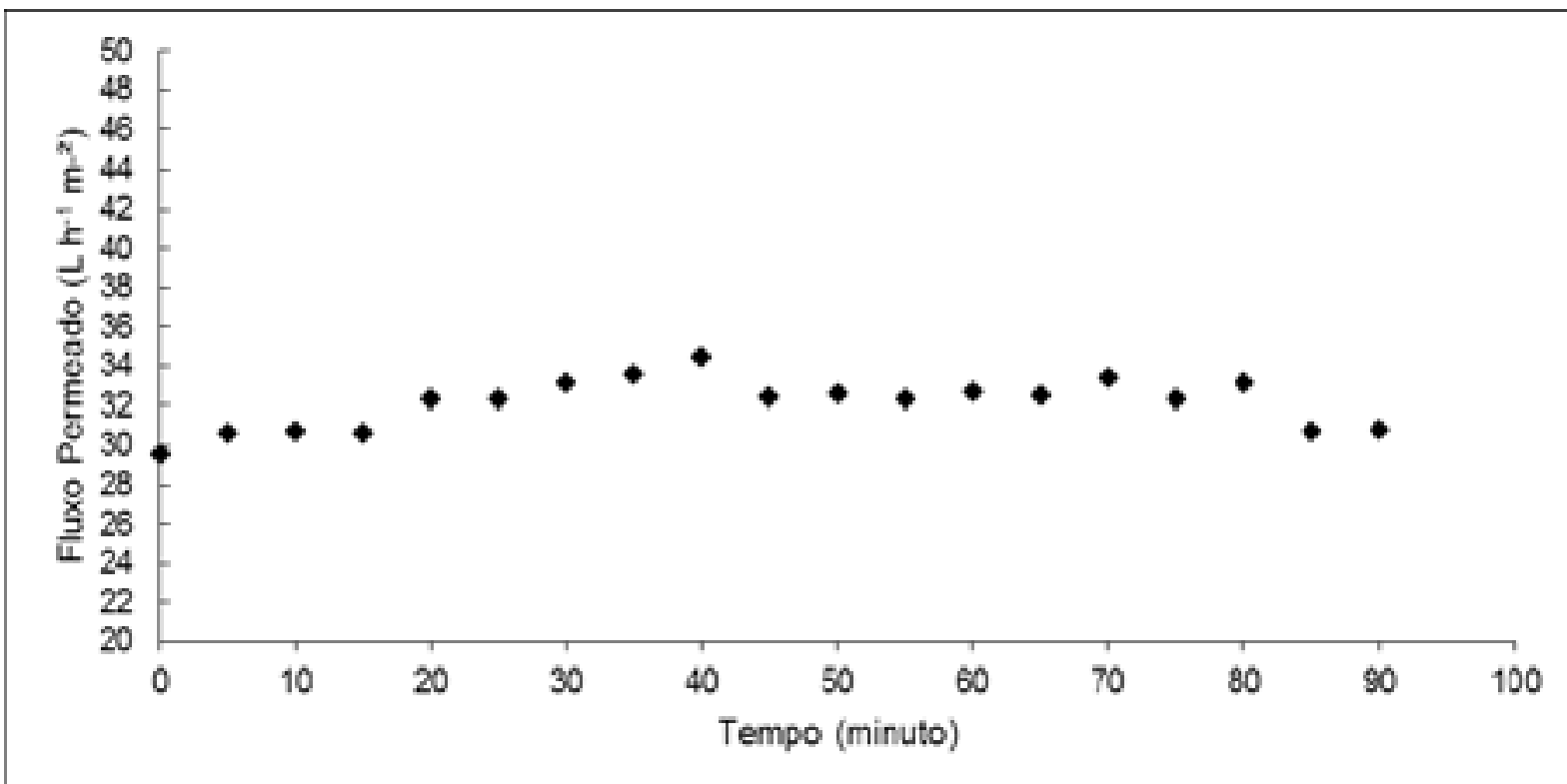


A qualidade do permeado encontrada neste ensaio, bem como a eficiência das membranas são apresentadas na Tabela 7. Para melhor verificação da qualidade do permeado, foram realizadas análises da demanda bioquímica de oxigênio $\left(\mathrm{DBO}_{5}\right)$ e Demanda Química de Oxigênio (DQO).

\section{Tabela 7 - Eficiência no tratamento de efluente de laticínio da membrana de MF seguida de UF.}

\begin{tabular}{|c|c|c|c|c|c|c|}
\hline \multirow{2}{*}{$\begin{array}{c}\begin{array}{c}\text { Membrana - } \\
\text { Pressão }\end{array} \\
\text { Fator de } \\
\text { Concentração }\end{array}$} & \multirow{2}{*}{$\begin{array}{c}\text { Amostra } \\
\text { Lote } 3 \\
-\end{array}$} & \multicolumn{2}{|c|}{$\begin{array}{c}\text { Membrana MF } \\
158-0,75 \text { bar }\end{array}$} & \multicolumn{2}{|c|}{$\begin{array}{c}\text { Membrana UF } \\
257-1,5 \text { bar }\end{array}$} & \multirow{2}{*}{$\begin{array}{c}\mathbf{U F}+ \\
\mathrm{E}(\%)\end{array}$} \\
\hline & & $\mathrm{Fc}=1,25$ & $\mathrm{E}(\%)$ & $\mathrm{Fc}=1,25$ & $\mathrm{E}(\%)$ & \\
\hline $\mathrm{ST}\left(\mathrm{mg} \mathrm{L}^{-1}\right)$ & 2.622 & 1.737 & 33,75 & 1.663 & 4,26 & 36,58 \\
\hline $\operatorname{STF}\left(\mathrm{mg} \mathrm{L}^{-1}\right)$ & 1.795 & 1.606 & 10,53 & 1.571 & 2,18 & 12,48 \\
\hline $\operatorname{STV}\left(\mathrm{mg} \mathrm{L}^{-1}\right)$ & 827 & 166 & 79,93 & 57 & 65,66 & 93,11 \\
\hline $\mathbf{P h}$ & 8,83 & 9,13 & - & 9,32 & - & - \\
\hline $\mathrm{DBO}\left(\mathrm{mg} \mathrm{L}^{-1}\right)$ & 467 & 15 & 96,79 & 11 & 26,67 & 97,64 \\
\hline $\begin{array}{c}\text { DQO (mg } \\
\left.\text { L }^{-1}\right)\end{array}$ & 894 & $<25$ & 97,20 & $<25$ & $\mathrm{NC}^{*}$ & $\approx 97,20$ \\
\hline
\end{tabular}

${ }^{*} N C=$ Não calculado.

Por meio da Tabela 7 é possível perceber que o tratamento por membrana de UF após a $\mathrm{MF}$ acrescenta uma eficiência na retenção de sólidos totais voláteis acima de $65 \%$ e para a $\mathrm{DBO}_{5}$ em torno de 27\%. Para os demais parâmetros não há retenção complementar considerável.

Realizando a MF seguida da UF, a retenção da DQO e da DBO foram bastante consideráveis (acima de 97\%), bem como a remoção de sólidos totais voláteis (93\%). As remoções de Turbidez e de Sólidos Sedimentáveis foram de 100\%.

Os parâmetros sólidos totais tiveram percentual de eficiência de retenção médio, de 36,58, enquanto a remoção de sólidos totais fixos foi pouco considerável, apenas 12,48\%. Comparandose com os ensaios E1 a E7 (Tabela 2), percebe-se que, mesmo com a realização do ensaio de MF seguida de UF, não houve elevação considerável na eficiência de remoção dos parâmetros sólidos totais e sólidos totais fixos.

Os resultados encontrados para o ensaio 7 foram comparados com os padrões de lançamento para efluentes da indústria de laticínios, Resolução no 70 de 2009, do Conselho Estadual de Meio Ambiente (CEMA).

A Tabela 8 contém os dados referentes aos padrões de lançamento de efluentes da indústria de laticínios e os resultados encontrados para a MF seguida de UF. 
Tabela 8 - Requisitos físico-químicos para o lançamento de efluentes e médias encontradas para a MF+UF.

\begin{tabular}{cccc}
\hline Parâmetro & Unid. & $\begin{array}{c}\text { Resolução } \\
\text { CEMA 70/2009 }\end{array}$ & MF+UF \\
\hline $\mathbf{p H}$ & - & $5-9$ & 9,32 \\
Turbidez & $\mathrm{NTU}$ & $2-10$ & 0 \\
DQO & $\mathrm{mg} \mathrm{L}^{-1}$ & 200 & $<25$ \\
DBO $_{5}$ & $\mathrm{mg} \mathrm{L}^{-1}$ & 50 & 11 \\
Sólidos & $\mathrm{mL} \mathrm{L}^{-1}$ & 1 & 0 \\
Sedimentáveis & $\mathrm{h}^{-1}$ & & \\
\hline
\end{tabular}

Os parâmetros para o lançamento do efluente nos corpos hídricos foram atendidos pelo tratamento por MF seguida da UF para os parâmetros: turbidez, $\mathrm{DQO}, \mathrm{DBO}_{5}$ e sólidos sedimentáveis. Para o $\mathrm{pH}$, o valor encontrado no efluente após o tratamento por membranas ficou acima do estabelecido na resolução.

\section{CONSIDERAÇÕES FINAIS}

Considerando-se os objetivos propostos, a metodologia utilizada e os resultados obtidos através dos processos de separação por membranas como pós-tratamento de efluente de laticínio, pode-se concluir:

O efeito da concentração de partículas na superfície das membranas de microfiltração e ultrafiltração na queda do fluxo permeado, no decorrer do tempo, ficou bastante evidente nos tratamentos realizados.

Comparando-se os padrões de lançamento para efluentes de indústrias de laticínios, Resolução CEMA no 70/2009 - Condições e Padrões de Lançamento de Efluentes Líquidos Industriais, mais especificamente o anexo 7 dessa resolução, com os melhores resultados para MF seguida de UF, pode-se verificar que os parâmetros de $\mathrm{DQO}, \mathrm{DBO}_{5}$, turbidez e sólidos sedimentáveis foram atendidos.

As membranas de MF e UF mostram eficiência considerável no tratamento de efluente de laticínio, especificamente na remoção de matéria orgânica, turbidez e sólidos. O presente estudo poderá servir de fundamento para demais indústrias de laticínios da região, com relação a adoção de processos de separação por membranas no tratamento de efluentes.

\section{REFERÊNCIAS}

ACERO, J. L.; BENITEZ, F.J.; LEAL, A. I.; REAL, F.J.; TEVA, F. Membrane filtration Technologies applied to municipal secondary effluents for potencial reuse. Journal of Hazardous Materials. P. 390-398, 2010.

AMARAL, M.C. S.; ANDRADE, L.H. de.; LANGE, L. C.; BORGES, C.P. Avaliação do emprego de microfiltração para remoção de fibras do efluente de branqueamento de polpa celulósica. Revista de Engenharia Sanitária e Ambiental. v. 18, n. 1, p. 65-74. Jan-mar 2013. 
ABNT - ASSOCIAÇÃO BRASILEIRA DE NORMAS TÉCNICAS.Planejamento de amostragem de efluentes líquidos e corpos receptores. Procedimento. NBR 9897. Rio de Janeiro, 1987ª. Rio de Janeiro: Preservação e técnicas de amostragem de efluentes líquidos e corpos receptores. Procedimento. NBR 9898. Rio de Janeiro: $1987^{\mathrm{b}}$.

AMERICAN PUBLIC HEALTH ASSOCIATION - APHA; AMERICAN WATER WORKS ASSOCIATION - AWWA; WATER ENVIROMENT FEDERATION - WEF. Standard methods for the examination of water and wastewater. 22 ed., Washington, DC: APHA, 2012.

BRIÃO, V. B.; TAVARES, C. R. G. Ultrafiltração como processo de tratamento para reúso de efluentes de laticínios. Revista de Engenharia Sanitária e Ambiental. Vol. 12, n. 2. Abr/jun, 2007, p. 134-138.

BULLÓN, J.; RENNOLA, L.; SALAZAR, F.; HOEGER, M.; CÁRDENAS, A.; ROJÁS, O.J.Tratamiento de aguas de circuitos cerrados de La industria papelera utilizando técnicas de separación por membranas. Revista Técnica de La Facultad de Ingenería Universidade Del Zulia. V. 30, n. especial, Maracaibo, 2007.

CONSELHO ESTADUAL DO MEIO AMBIENTE. Resolução no 70, de 1 de outubro de 2009 - Condições e padrões de lançamento de efluentes líquidos industriais.

FAPPI, Devanir André. Micro e ultrafiltração como pós-tratamento para o reúso de efluentes de abatedouro e frigorífico de suínos. 2015.126 p. Dissertação (Mestrado em Tecnologias Ambientais). Universidade Tecnológica Federal do Paraná. Medianeira, 2015.

FIELD, R.; WU, D.; HOWELL, J. A.; GUPTA, B. B. W. Critical Flux concept for microfiltration fouling. Journal of Membrane Science. V. 100, p. 259-272, 1995.

GIACOBBO, A.; RODRIGUES, M. A. S.; BERNARDES, A. M.; FERREIRA, J. Z.; MENEGUZZI, A. Microfiltração aplicada ao tratamento de efluentes de curtume. In: VII Simpósio Internacional de Qualidade Ambiental. Porto Alegre, Rio Grande do Sul, 2010.

HABERT, A. C.; BORGES, C. P.; NOBREGA, R. Processos de separação por membranas. Rio de Janeiro: E-papers, 2006.

HASAN, A.; PELUSO, C. R.; HULL, T. S.; FIESCHKO, J.; CHATTERJEE, S. G. A surface-renewall model of cross-flow microfiltration. Brazilian Journal of Chemical Engineering. V. 30, n. 1, p. 167-186. Jan/mar, 2013.

LAUTENSCHLAGER, R. S.; FILHO, S. S. F.; PEREIRA, O. Modelação matemática e otimização operacional de processos de membrana de ultrafiltração. Revista de Engenharia Sanitária e Ambiental. v. 14, n. 2, p. 215-222. Abr/jun 2009. 
MAGANHA, M.F.B. (Elab.). Guia técnico ambiental da indústria de produtos lácteos - Série P+L. São Paulo: CETESB, 2008.

MILLER JR., G. T. Ciência Ambiental. São Paulo: Cencage Learning, 2008.

MIERZWA, J. C.; HESPANHOL, I. Água na indústria: uso racional e reúso. São Paulo: Oficina de Textos, 2005.

NETA, L. S. de F.; HABERT, A. C.; BORGES, C. P. Cerveja microfiltrada: processo e qualidade. Brazilian Journal of Food Technology. 2005.

PAM MEMBRANAS. Manual de instalação, operação e manutenção. Unidade de MF/UF/NF de bancada, 2012.

SARMENTO, L. A. V. Obtenção e separação de polifenóis de sementes de cacau por extração supercrítica associada a membranas. 2007. 103 p. Tese (Doutorado em Engenharia Química). Universidade Federal de Santa Catarina, Florianópolis, 2007.

SCHNEIDER, R. P.; TSUTYIA, M. T. Membranas Filtrantes para o tratamento de água, esgoto e água de reuso. São Paulo: ABES, 2001.

SCHMITT, D. M. F.; VEIT, M. T.; BERGAMASCO, R.; VIEIRA, A. M. S.; FAGUNDES-KLEN, M. R. Ultrafiltration Combined with Coagulation/Flocculation/ Sedimentation Using Moringa oleifera as Coagulant to Treat Dairy Industry Wastewater. Water Air Soil Pollut. V. 224, n. 1682, p. 1-10, 2013.

SONG, L. Flux decline in crossflow microfiltration and ultrafiltration: mechanisms and modeling of membrane fouling.Journal of Membrane Science. V.139, p. 183-200.1998.

VIDAL, C. M. de S.; CAMPOS, J. R. Coagulação associada à microfiltração para o tratamento avançado de esgoto sanitário. Revista Ambiência. Guarapuava, PR v.5 n.1 p.101 - 114 Jan./Abr. 2009.

WESCHENFELDER, S. E.; BORGES, C.P.; CAMPOS, J. C. Avaliação de membranas para o tratamento de água proveniente do processo de extração de petróleo. Revista Ambiente e Água. V. 10, n. 2, abr/jun, 2015. 